\title{
1,2-Diarylbenzene as fast T-type photochromic switch
}

Daichi Kitagawa, Tatsumoto Nakahama, Yoshihiro Nakai, Seiya Kobatake

\begin{tabular}{|c|l|}
\hline Citation & Journal of Materials Chemistry C, 7(10); 2865-2870 \\
\hline Issue Date & $2019-03-14$ \\
\hline Type & Journal Article \\
\hline Textversion & Author \\
\hline Relation & $\begin{array}{l}\text { The following article has been accepted by Journal of Materials Chemistry C. After it } \\
\text { is published, it will be found at https://doi.org/10.1039/C8TC05357J. } \\
\text { Please cite only the published version. }\end{array}$ \\
\hline DOI & $10.1039 / \mathrm{C} 8 \mathrm{TC} 05357 \mathrm{~J}$ \\
\hline
\end{tabular}

Self-Archiving by Author(s)

Placed on: Osaka City University 


\title{
J. Mater. Chem. C
}

\section{ARTICLE}

\section{1,2-Diarylbenzene as Fast T-type Photochromic Switch}

\author{
Daichi Kitagawa*, Tatsumoto Nakahama, Yoshihiro Nakai and Seiya Kobatake*
}

Received 00th January 20xx, Accepted 00th January 20xx

DOI: $10.1039 / \times 0 x \times 00000 x$

www.rsc.org/

\begin{abstract}
Fast T-type photochromic molecules that isomerize only under photoirradiation are promising materials for ophthalmic lenses, real-time holography, security systems, and super-resolution fluorescence microscopy. In this study, we successfully developed a novel fast T-type photochromic molecular system, 1,2-diarylbenzene (DAB), by introducing tetrafluorobenzene to the ethene bridge unit of the typical P-type photochromic diarylethene. DAB changed from colorless to blue only when irradiated with ultraviolet light because it underwent photocyclization and fast thermal cycloreversion with a half-life of 130 $\mathrm{ms}$ at room temperature. The dramatic acceleration of thermal cycloreversion was due to the significant increase in the energy gap between the open- and closed-ring isomers and decrease in activation energy at the ground state. In addition, DAB could undergo fast photochromic reaction even in the solid state. Thus, introduction of a benzene ring to the ethene bridge unit would lead to the development of new functions for $6 \pi$-electron photochromic systems.
\end{abstract}

\section{Introduction}

Utilizing light as external stimulus to modulate physicochemical properties, such as conductivity, fluorescence, and magnetism, has attracted much attention because it offers precise spatial control without the need for direct physical contact. ${ }^{1-3}$ In many cases, a photochromic molecule is incorporated into the system as a photoswitch. Investigation of the fundamental properties of these molecules is quite essential to improving photoswitching abilities. Control of the thermal bleaching reaction rate of a colored isomer is especially vital for practical applications. ${ }^{4,5}$ Abe and co-workers developed fast photochromic molecules, specifically hexaarylbiimidazole derivatives, that have a half-life $\left(t_{1 / 2}\right)$ of a few tens of $m s$ for thermal bleaching. ${ }^{6,7}$ The concept of molecular design was to inhibit the diffusion of radicals by crosslinking two imidazole units. The molecules could undergo photoisomerization only under photoirradiation and quickly return to the original state as soon as irradiation stopped. After this remarkable finding, the tuning of the thermal bleaching reaction rate of T-type compounds, such as $N, N^{\prime}$-disubstituted indigos and phenylazoindole, has been investigated. ${ }^{8,9}$ Fast photochromic molecules are promising materials for real-time holography, ${ }^{10,11}$ super-resolution fluorescence microscopy, ${ }^{12,13}$ fast photomechanical systems, ${ }^{14,15}$ and others; ${ }^{16-19}$ thus, development of novel types of these molecules would provide new areas for research and technology.

Department of Applied Chemistry, Graduate School of Engineering, Osaka City University, 3-3-138 Sugimoto, Sumiyoshi-ku, Osaka 558-8585, Japan. E-mail:kitagawa@osaka-cu.ac.jp; kobatake@a-chem.eng.osaka-cu.ac.jp; Fax: +8166605 2797; Tel: +81666052797

†Electronic Supplementary Information (ESI) available: Detailed experimental data (Fig. S1-S7 and Table S1-S10), and the movie of the fast photochromism (Video S1). See DOI: 10.1039/x0xx00000x
In line with this, we focused on the development of $6 \pi$ electron photocyclization/thermal cycloreversion reaction of diarylethene (DAE) photoswitches. Most investigated DAEs have perfluorocyclopentene as the ethene bridge unit, and these molecules are known as one of the most promising P-type photoswitches because of their excellent properties such as high durability, high sensitivity, rapid response, and reactivity in the solid state. ${ }^{20}$ Thus, P-type DAE photoswitches have potential applications as optical memories and switches, ${ }^{2,21-23}$ and photoactuators. ${ }^{24-26}$ In addition, DAEs can be transformed into T-type photoswitches by introducing various substituents. ${ }^{27}$ The thermal stability of a colored closed-ring isomer can be tuned by three factors: (i) aromatic stabilization energy of the aryl groups; (ii) electron-withdrawing substituents in the aryl groups; and (iii) steric hindrance of the substituents at reactive positions. ${ }^{28}$ These relate to the energy difference $(\Delta E)$ between the colored closed-ring isomer and colorless open-ring isomer in the ground state; 29,30 a larger $\Delta E$ leads to an increase in the thermal cycloreversion reactivity. Furthermore, several groups have investigated the thermal stability of DAEs having aromatic rings as the ethene bridge unit and found that the aromaticity of the rings has a positive effect on thermal cycloreversion reactivity (i.e., the higher aromaticity, the higher thermal cycloreversion reactivity). ${ }^{31-33}$ In particular, Kawai et al. reported that a photochromic terarylene molecule, a DAE analog, could undergo thermal cycloreversion with $t_{1 / 2}$ of $5.4 \mathrm{~s}$ at 293 K. ${ }^{32}$ However, to the best of our knowledge, a fast photochromic molecule with $t_{1 / 2}$ ranging from $\mu$ s to ms based on the $6 \pi$-electron photocyclization/thermal cycloreversion reaction of DAEs has not been successfully constructed.

Herein, we report on 1,2-diarylbenzene (DAB) that functions as fast photochromic switch. The ethene bridge unit of a representative DAE derivative, 1,2-bis(2-methyl-5-phenyl-3thienyl)perfluorocyclopentene (1), ${ }^{34}$ was replaced with 
(a)

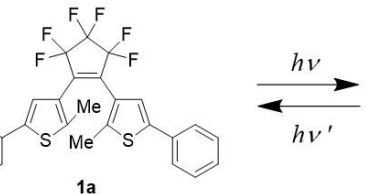

(b)
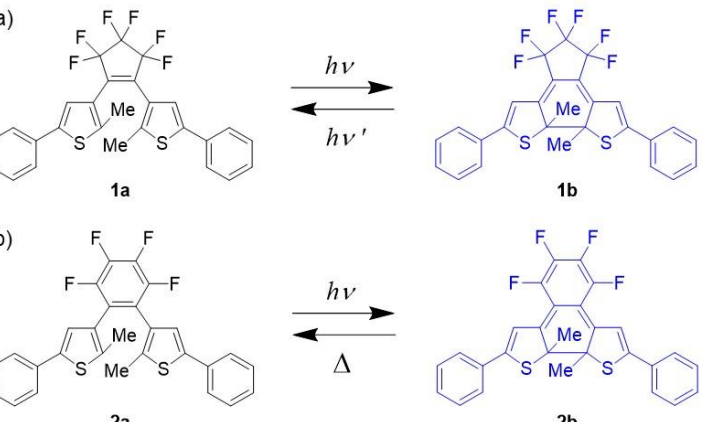

$1 \mathrm{~b}$

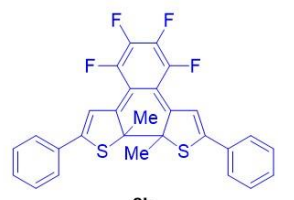

$2 b$

Scheme 1 Molecular structures of (a) DAE and (b) DAB used in this work.

tetrafluorobenzene

in

1,2-bis(5-phenyl-2-methyl-3-

thienyl)tetrafluorobenzene (2) (Scheme 1).

\section{Results and discussion}

\section{Molecular design and synthesis}

To increase the thermal cycloreversion reactivity, a benzene ring, which has high aromatic stabilization energy, was introduced to the ethene bridge unit of $\mathbf{1}$ to form $\mathbf{2}$, as shown in Scheme 1 . The $\Delta E$ values of $\mathbf{1}$ and $\mathbf{2}$ were calculated by density functional theory (DFT) at the B3LYP/6-31G(d) level and are summarized in Table S1. The $\Delta E$ of $2\left(111.04 \mathrm{~kJ} \mathrm{~mol}^{-1}\right)$ is significantly larger than that of $1\left(56.39 \mathrm{~kJ} \mathrm{~mol}^{-1}\right)$. In addition, the activation energies $\left(E_{\mathrm{a}}\right)$ for the thermal cycloreversion of $\mathbf{1}$ and $\mathbf{2}$ were also calculated and are summarized in Table S1. The $E_{\mathrm{a}}$ of $2\left(57.46 \mathrm{~kJ} \mathrm{~mol}^{-1}\right)$ is significantly smaller than that of 1 $\left(128.15 \mathrm{~kJ} \mathrm{~mol}^{-1}\right)$. We could not observe any specific steric effect or intramolecular interaction in the transition states (Fig. S1). These results suggest that $\mathbf{2}$ potentially undergoes a fast photochromic reaction due to a decrease of $E_{\mathrm{a}}$ based on an increase of $\Delta E$ by introducing of benzene ring with high aromatic stabilization energy to the ethene bridge. Although non-fluorinated $D A B$ and its derivatives have been previously synthesized, $^{35,36}$ there have been no studies on their photocyclization reactivities. In a recent work, Milić et al. assumed that the photocyclization of DABs may be prohibited owing to the high aromaticity of the benzene ring. ${ }^{33}$ However, we hypothesize that photocyclization reactivity was not observed because thermal cycloreversion is too fast. To investigate the photochromic reactivity of DABs, we successfully synthesized 2a through Suzuki-Miyaura coupling reaction of 3-bromo-2-methyl-5-phenylthiophene ${ }^{34}$ and 1,2dibromotetrafluorobenzene (Scheme 2 in Experimental section) in $42 \%$ yield.

\section{Photochromic reaction behavior in solution}

Compound $\mathbf{2 a}$ in $n$-hexane undergoes a photochromic reaction involving a color change from colorless to blue only while the solution is irradiated with UV (313 nm) light (Fig. 1 and Video S1). This indicates that the thermal cycloreversion rate is much faster than the diffusion rate of the closed-ring isomer at room temperature, resulting in a fast photochromic reaction. Further experiments were conducted to reveal the photochemical and

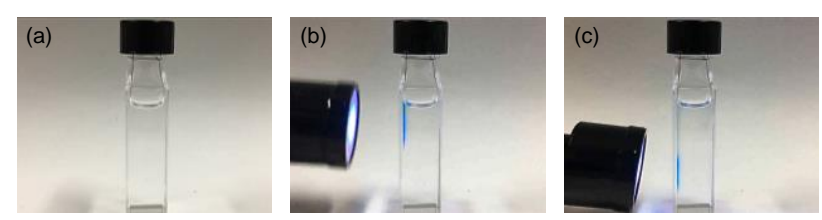

Fig. 1 Photochromic reaction behavior of $2 \mathrm{a}$ in $n$-hexane $\left([2 \mathrm{a}]=1.0 \times 10^{-3} \mathrm{M}\right)$. (a) Before photoirradiation and upon irradiation with $313 \mathrm{~nm}$ light $\left(120 \mathrm{~mW} \mathrm{~cm}^{-2}\right)$ to (b) the upper part and (c) the lower part of the quartz cell.

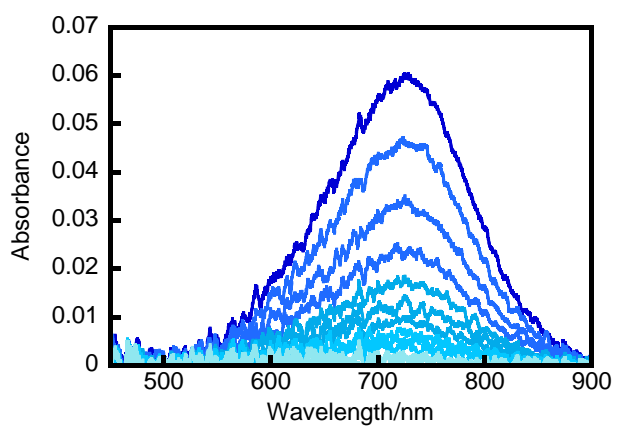

Fig. 2 Transient absorption spectra of $\mathbf{2 b}$ in $n$-hexane at $298 \mathrm{~K}\left([\mathbf{2 a}]=1.2 \times 10^{-4}\right.$ M). Each spectrum was recorded at $40 \mathrm{~ms}$ intervals after irradiation with $313 \mathrm{~nm}$ light $\left(120 \mathrm{~mW} \mathrm{~cm}^{-2}\right)$.

thermal cycloreversion reactions in detail. Firstly, the photochromic reactivity upon irradiation with UV light was investigated. The absorption maximum of $2 a$ is $285 \mathrm{~nm}(\varepsilon=$ $31000 \mathrm{M}^{-1} \mathrm{~cm}^{-1}$ ) in $n$-hexane (Fig. S2), which is similar to that of 1a $\left(\lambda_{\max }=280 \mathrm{~nm}, \varepsilon=35600 \mathrm{M}^{-1} \mathrm{~cm}^{-1}\right) \cdot{ }^{34} \mathrm{Fig} .2$ shows the transient absorption spectrum of $2 \mathrm{a}$ in $n$-hexane at $298 \mathrm{~K}$. Upon irradiation with $313 \mathrm{~nm}$ light, a new absorption band appears at around $730 \mathrm{~nm}$, which can be assigned to the closed-ring isomer $\mathbf{2 b}$. This absorption band is largely red-shifted relative to that of 1b in $n$-hexane $\left(\lambda_{\max }=575 \mathrm{~nm}\right)$, which is consistent with the UVvis spectrum calculated by time-dependent DFT at the B3LYP/631G(d) level (Fig. S3). The red shift is due to the decrease in the HOMO-LUMO gap caused by the longer $\pi$-conjugation of $\mathbf{2 b}$ compared with 1b (Fig. S4 and Table S2). It is difficult to quantitatively evaluate the photochemical reactivity of $\mathbf{2} \mathbf{a}$ at room temperature owing to the fast thermal cycloreversion. Therefore, we examined the absorption changes upon

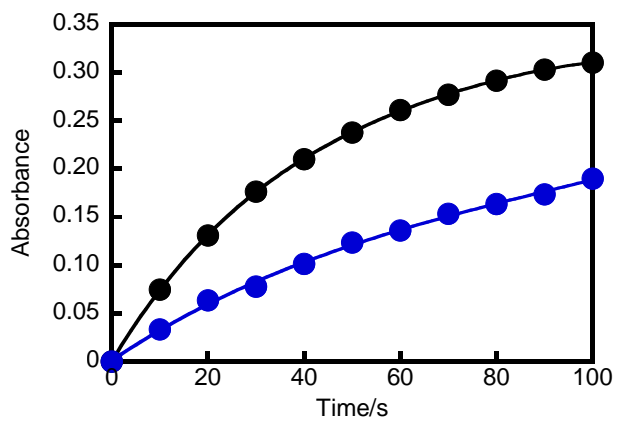

Fig. 3 Absorption changes of $\mathbf{1 b}(\bullet)$ and $\mathbf{2 b}(\bullet)$ upon irradiation with $313 \mathrm{~nm}$ light $\left(1.5 \mathrm{~mW} / \mathrm{cm}^{2}\right)$ at $193 \mathrm{~K}$. $n$-Hexane solutions of $1 \mathrm{a}$ and $2 \mathrm{a}$ have the same absorbance at $313 \mathrm{~nm}\left(\mathrm{Abs}_{313 \mathrm{~nm}}=\mathbf{0 . 3}\right)$. Absorbance of $\mathbf{1} \mathbf{b}$ and $\mathbf{2} \mathbf{b}$ was recorded at $575 \mathrm{~nm}$ and $745 \mathrm{~nm}$, respectively. 
irradiation with $313 \mathrm{~nm}$ light at $193 \mathrm{~K}$ of $n$-hexane solutions of $\mathbf{1 a}$ and $\mathbf{2 a}$, which have the same absorbance at that wavelength (Fig. 3). The absorption changes of $\mathbf{2 a}$ versus the irradiation time are almost half than those of 1a. The estimated photocyclization quantum yield of $\mathbf{2}$ is around 0.3 assuming that the molar extinction coefficients of the closed-ring isomers $\mathbf{1 b}$ and $\mathbf{2} \mathbf{b}$ are constant. This is a fairly rough estimate, though enough to indicate that the photocyclization reactivity is sufficiently large. In addition, in the case of Fig. 2, the isomerization rate from $\mathbf{2 a}$ to $\mathbf{2} \mathbf{b}$ under irradiation with UV light was calculated to be ca. $\mathbf{3} \%$ based on the same assumption as described above.

\section{Thermal cycloreversion reactivity}

Secondly, to quantitatively assess the thermal cycloreversion reactivity of $\mathbf{2} \mathbf{b}$, the absorption changes over time at various temperatures were investigated, as shown in Fig. 4a. The kinetic analysis of the thermal cycloreversion reaction is detailed in Supplementary Information. The decay curves obey first-order kinetics, and the rate constant $(k)$ of thermal cycloreversion can
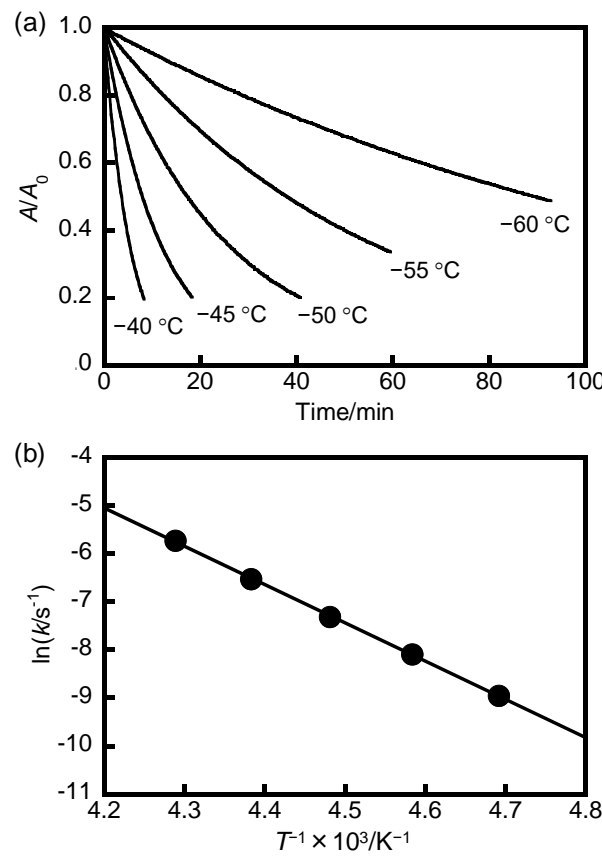

Fig. 4 (a) Absorption decay curves of $\mathbf{2 b}$ monitored at $745 \mathrm{~nm}$ in $n$-hexane at various temperatures, and (b) temperature dependence of the rate constant $k$ for thermal cycloreversion of the compound.

Table 1. Kinetic parameters for thermal cycloreversion of $\mathbf{1} \mathbf{b}$ and $\mathbf{2} \mathbf{b}$

\begin{tabular}{ccccc}
\hline & $E_{\mathrm{a}} / \mathrm{kJ} \mathrm{mol}^{-1}$ & $A / \mathrm{s}^{-1}$ & $\mathrm{k} / \mathrm{s}^{-1}$ at $298 \mathrm{~K}$ & $t_{1 / 2}$ at $298 \mathrm{~K}$ \\
\hline $\mathbf{1 \mathbf { b } ^ { a }}$ & 139 & $1.0 \times 10^{13}$ & $4.4 \times 10^{-12}$ & $5000 \mathrm{y}$ \\
$\mathbf{2 b}$ & 66 & $2.1 \times 10^{12}$ & 5.3 & $130 \mathrm{~ms}$ \\
\hline
\end{tabular}

a ref 34.
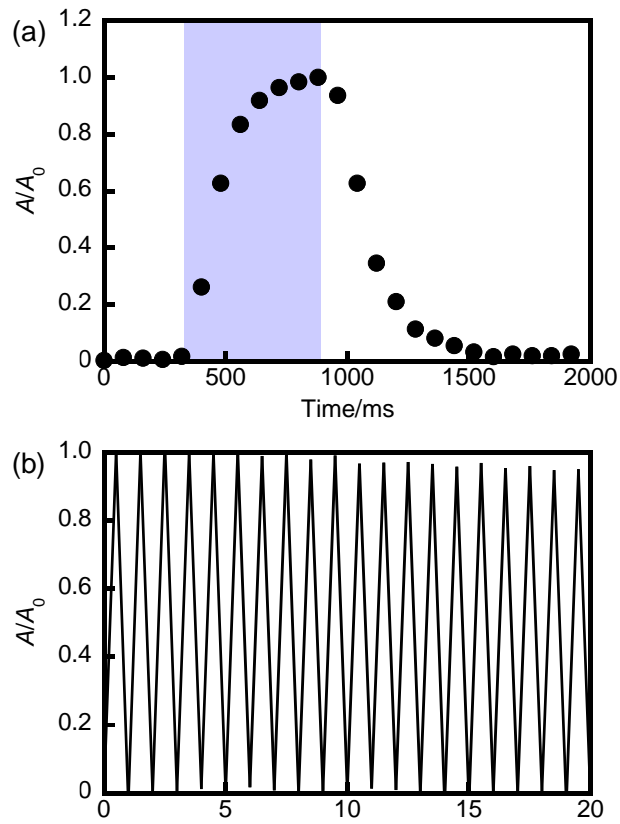

Cycle Number

Fig. 5 (a) Absorbance change of $\mathbf{2 b}$ in $n$-hexane $\left([\mathbf{2 a}]=2.4 \times 10^{-5} \mathrm{M}\right)$ relative to time upon photoirradiation at $313 \mathrm{~nm}\left(120 \mathrm{~mW} \mathrm{~cm}^{2}\right.$, purple region) for $0.5 \mathrm{~s}$ and thermal bleaching at $298 \mathrm{~K}$. Absorbance of $\mathbf{2} \mathbf{b}$ was calculated by averaging the absorbance from $700 \mathrm{~nm}$ to $800 \mathrm{~nm}$. Each absorbance was recorded at $80 \mathrm{~ms}$ intervals. (b) Repeated cycles upon alternating photoirradiation at $313 \mathrm{~nm}$ (120 $\mathrm{mW} \mathrm{\textrm {cm } ^ { - 2 }}$ ) for $0.5 \mathrm{~s}$ and thermal bleaching at $298 \mathrm{~K}$.

be determined from the slope of the linear plot (Fig. S5 and Table S3). Fig. $4 \mathrm{~b}$ shows the temperature dependence of $k$, that is, $k$ increases with increasing temperature. The $E_{\mathrm{a}}$ and frequency factor $(A)$ of thermal cycloreversion can be determined from the slope and intercept of the linear plot, and the results are summarized in Table 1 . The estimated $E_{\mathrm{a}}$ and $A$ for $\mathbf{2 b}$ are $66 \mathrm{~kJ} \mathrm{~mol}^{-1}$ and $2.1 \times 10^{12} \mathrm{~s}^{-1}$, respectively. The $E_{\mathrm{a}}$ is similar to that calculated by DFT. $A$ hardly differed from previously reported values for DAEs $\left(A=10^{11}-10^{13} \mathrm{~s}^{-1}\right)$. On the other hand, $E_{\mathrm{a}}$ is much lower than those found in literature. ${ }^{27}$ Furthermore, the $E_{\mathrm{a}}$ of $\mathbf{2} \mathbf{b}$ is notably smaller by ca. $20 \mathrm{~kJ} \mathrm{~mol}^{-1}$ than that of terarylene, which underwent thermal cycloreversion with $t_{1 / 2}$ of $5.4 \mathrm{~s}$ at $293 \mathrm{~K} .{ }^{32}$ The calculated $k$ of $\mathbf{2 b}$ at $298 \mathrm{~K}$ is $5.3 \mathrm{~s}^{-1}$, while surprisingly, the calculated $t_{1 / 2}$ is 130 ms. These results indicate that thermal cycloreversion was drastically accelerated by introducing the benzene ring to the ethene bridge unit, which can be ascribed to the significant decrease in $E_{\mathrm{a}}$.

\section{Fatigue resistance property}

Fatigue resistance is necessary for practical photoswitches; thus, to confirm the durability of the DAB photoswitch, repeated cycles of photochemical and thermal cycloreversion reactions were conducted, as shown in Fig. 5. Irradiation with $313 \mathrm{~nm}$ light for $0.5 \mathrm{~s}$ and thermal cycloreversion at $298 \mathrm{~K}$ was alternately repeated for $\mathbf{2 a}$ in $n$-hexane. Fig. $5 a$ shows the absorbance change relative to time in the first cycle. Upon irradiation with UV light, the absorbance of $\mathbf{2} \mathbf{b}$ increased. After irradiation ceased, the absorbance decreased owing to thermal 


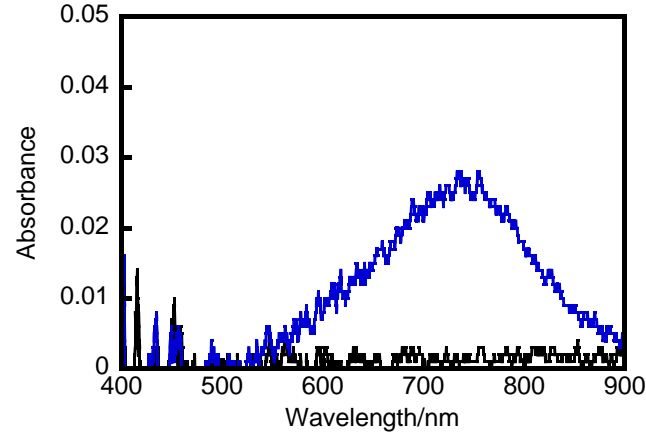

Fig. 6 Absorption spectra of the PMMA film doped with 50 wt\% of $2 a$ at $298 \mathrm{~K}$ without (black line) and with $313 \mathrm{~nm}$ light $\left(120 \mathrm{~mW} \mathrm{~cm}^{-2}\right)$ (blue line).

cycloreversion. After 20 cycles, the absorbance of $\mathbf{2} \mathbf{b}$ hardly changed in comparison to that in the first cycle (Fig $5 \mathrm{~b}$ ). In this case, however, the isomerization ratio from $\mathbf{2 a}$ to $\mathbf{2} \mathbf{b}$ under irradiation with UV light is ca. $3 \%$ at $298 \mathrm{~K}$ as mentioned above. To investigate the fatigue resistance property at the high isomerization ratio, irradiation with $313 \mathrm{~nm}$ light for $150 \mathrm{~s}$ at $193 \mathrm{~K}$ and thermal cycloreversion at room temperature was alternately repeated for $\mathbf{2 a}$ in $n$-hexane (Fig. S6). The absorbance of $\mathbf{2} \mathbf{b}$ hardly decreased after $\mathbf{2 0}$ cycles. These results indicate that $2 \mathrm{a}$ has high fatigue resistance for repeated photocyclization and thermal cycloreversion reactions.

\section{Photochromic reaction behavior in solid state}

Finally, the fast photochromic reaction of $\mathbf{2 a}$ in the solid state was demonstrated. When $2 \mathrm{a}$ was recrystallized from $n$-hexane, a colorless block crystal was obtained. Single-crystal X-ray crystallographic analysis of $\mathbf{2} \mathbf{a}$ was performed, and the result is summarized in Table S4. The crystal system and space group are orthorhombic and $P 2_{1} 2_{1} 2_{1}$, respectively. The crystals have one molecule in the asymmetric unit. Unfortunately, $2 \mathbf{a}$ exists in a non-photoreactive parallel conformation in the crystal (Fig. S7). To confirm the photoresponsibility of $\mathbf{2 a}$ in the solid state, a polymer film containing $2 \mathrm{a}$ was prepared by casting a toluene solution containing the compound and poly(methyl methacrylate) (PMMA) (1:1 w/w) on a slide glass and drying it in air. Upon irradiation with $313 \mathrm{~nm}$ light, the colorless film turns blue and an absorption band appears at around $740 \mathrm{~nm}$, as shown in Fig. 6. After irradiation ceased, the absorption band rapidly disappeared owing to thermal cycloreversion. Thus, the photocyclization and fast thermal cycloreversion reactions of $\mathbf{2 a}$ can be observed even in the polymer film. This result clearly indicates that the DAB with the photoreactive anti-parallel conformation can undergo the fast photochromic reaction even in the rigid environment. This is one of the advantages of $6 \pi$ electron photocyclization/thermal cycloreversion system, which requires only small molecular geometry change during the isomerization. We are now in the process of synthesizing various DAB derivatives to investigate the photoresponsibility in the crystalline state for application toward fast photomechanical systems.

\section{Experimental}

\section{General}

Solvents used were of spectroscopic grade and purified by distillation before use. ${ }^{1} \mathrm{H}$ NMR $(300 \mathrm{MHz})$ spectra were recorded on a Bruker AV-300N spectrometer with tetramethylsilane as the internal standard. High-resolution mass spectra (HRMS) were obtained on a Bruker FT-ICR/solariX mass spectrometer. The matrix-assisted laser desorption/ionization (MALDI) was used as an ionization technique. trans-2-[3-(4-tert-Butylphenyl)-2-methyl-2propenylidene]malononitrile (DCTB) was used as matrix. Geometry optimizations and harmonic frequency calculations of open-ring isomers, closed-ring isomers, and transition states were performed using Gaussian09 Rev.C.01 program package. The transition-state search was performed by using Opt=TS keyword using Berny algorithm to optimize to a transition state rather than a local minimum. Each stationary point was characterized by the number of imaginary frequencies ( $\mathrm{N} / \mathrm{mag}=$ 1 for transition state and NImag $=0$ for the local minimum) and by zero point vibrational energies. To follow unrestricted KohnSham solution, the broken-symmetry guess was generated and followed using keyword Guess (mix, always). The B3LYP level of DFT was used in combination with a $6-31 G(d)$ basis set. TD-DFT calculation was performed at the B3LYP/6-31G(d) level using the optimized molecular structures. Single crystal X-ray crystallographic analysis was carried out using a Rigaku AFC/Mercury CCD diffractometer with $\mathrm{MoK}_{\alpha}$ radiation $(\lambda=$ $0.71073 \AA$ ) monochromated by graphite. The crystal structures were solved by a direct method using SIR92 and refined by the full matrix least-squares method on $F^{2}$ with anisotropic displacement parameters for non-hydrogen atoms using SHELXL-2014. UV-Vis absorption spectra were measured using a JASCO V-560 absorption spectrometer. The light power was measured using a Neoark PM-335A power meter.

\section{Photochemical Reaction}

Transient absorption spectra were measured using a Nikon ECLIPSE E600POL polarizing optical microscope equipped with Ocean Optics USB4000 fiber multichannel analyzer as the photodetector. Photoirradiation was carried out using a $200 \mathrm{~W}$ mercury-xenon lamp (MORITEX MSU-6) as a light source. Monochromatic light was obtained by passing the light through a band-pass filter. Photochemical reaction at low temperature was carried out in $n$-hexane as follows. Photoirradiation was carried out using a $300 \mathrm{~W}$ xenon lamp (Asahi Spectra MAX-301) as a light source. Monochromatic light was obtained by passing light through a band-pass filter. Photocyclization reaction was followed by absorption spectra. The samples were not degassed. The optical quartz cell containing samples was placed in a cryostat for spectroscopy (UNISOKU CoolSpek UV/CD) during the photochemical reaction.

\section{Thermal Bleaching Reaction}

The thermal bleaching reaction of diarylbenzene closed-ring isomer was carried out in $n$-hexane as follows. The diarylbenzene open-ring isomer was put in an optical quartz cell. 
The solution in the cell was irradiated with $313 \mathrm{~nm}$ light to give the closed-ring isomer at the measurement temperature. Photoirradiation was carried out using a $300 \mathrm{~W}$ xenon lamp (Asahi Spectra MAX-301) as a light source. Monochromatic light was obtained by passing the light through a band-pass filter. The cell was placed in a cryostat for spectroscopy (UNISOKU Coolspek UV/CD) during the thermal bleaching reaction.

\section{Materials}

Chemicals used for synthesis were commercially available and used without further purification. DAB 2a was synthesized as shown in Scheme 2.

\section{1,2-Bis(5-phenyl-2-methyl-3-thienyl)tetrafluorobenzene (2a).}

3-Bromo-2-methyl-5-phenylthiophene ${ }^{34}(520 \mathrm{mg}, 2.1 \mathrm{mmol})$ was dissolved in anhydrous tetrahydrofuran (THF) $(15 \mathrm{~mL})$ under argon atmosphere. 1.6 $\mathrm{M} \mathrm{n}$-BuLi hexane solution $(1.3 \mathrm{~mL}$, $2.1 \mathrm{mmol}$ ) was slowly added dropwise to the solution at $-78{ }^{\circ} \mathrm{C}$, and the mixture was stirred for $2 \mathrm{~h}$. Tri- $n$-butyl borate $(1.0 \mathrm{~mL}$, $3.7 \mathrm{mmol}$ ) was slowly added to the solution at the temperature, and the mixture was stirred for $2 \mathrm{~h}$. An adequate amount of distilled water was added to the mixture to quench the reaction. The reaction mixture was acidified by $\mathrm{HCl}$ aqueous solution and extracted with ether. The organic layer was extracted with water after adding $\mathrm{NaOH}$ aqueous solution. The white precipitate of 2-methyl-5-phenyl-3-thienyl-boronic acid was fabricated by adding $\mathrm{HCl}$ aqueous solution to the water layer, washed with a large amount of water, and filtered to give 200 mg yield. The white precipitate of 2-methyl-5-phenyl-3-thienyl boronic acid was used for the next reaction without further purification. 2-Methyl-5-phenyl-3-thienyl boronic acid $(200 \mathrm{mg}$ $0.92 \mathrm{mmol}$ ), 1,2-dibromotetrafluorobenzene (120 mg, 0.40 $\mathrm{mmol}$ ), tetrakis(triphenylphosphine)palladium(0) $(50 \mathrm{mg}, 0.043$ $\mathrm{mmol}$ ), and $20 \mathrm{wt} \% \mathrm{Na}_{2} \mathrm{CO}_{3}$ aqueous solution $(2.5 \mathrm{~mL})$ were added to THF $(30 \mathrm{~mL})$, and the mixture was refluxed for $8 \mathrm{~h}$. The reaction mixture was neutralized by $\mathrm{HCl}$ aqueous solution, extracted with ether, washed with brine, dried over $\mathrm{MgSO}_{4}$, filtered, and concentrated in vacuo. The crude product was purified by column chromatography on silica gel using $n$-hexane as the eluent to give $81 \mathrm{mg}$ of $2 \mathrm{a}$ in $42 \%$ yield based on $1,2-$ dibromotetrafluorobenzene. $2 \mathrm{a}:{ }^{1} \mathrm{H}$ NMR $\left(300 \mathrm{MHz}, \mathrm{CDCl}_{3}, \mathrm{TMS}\right)$ $\delta=2.15-2.27\left(\mathrm{br}, 6 \mathrm{H}, \mathrm{CH}_{3}\right), 6.69-6.82(\mathrm{br}, 2 \mathrm{H}$, Aromatic $\mathrm{H}), 7.20$ $7.40\left(\mathrm{~m}, 10 \mathrm{H}\right.$, Aromatic H). ${ }^{13} \mathrm{C} \mathrm{NMR}\left(75 \mathrm{MHz}, \mathrm{CDCl}_{3}\right) \delta=14.08$, $125.39,125.78,127.52,128.67,128.97,134.17,140.71$. HR-MS (MALDI) $\mathrm{m} / \mathrm{z}=494.0780\left(\mathrm{M}^{+}\right)$. Calcd. for $\mathrm{C}_{28} \mathrm{H}_{18} \mathrm{~F}_{4} \mathrm{~S}_{2}{ }^{+}=494.0781$.
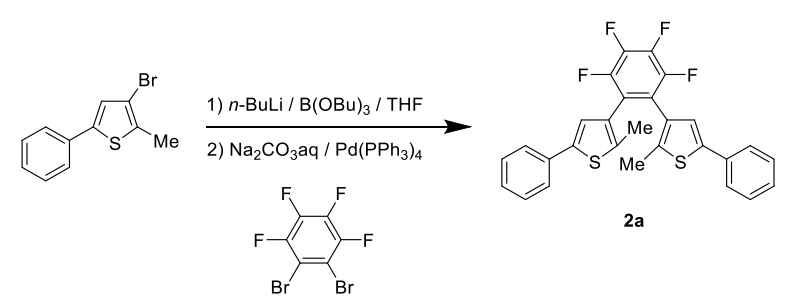

Scheme 2 Synthetic route of DAB 2 a.

\section{Conclusions}

In conclusion, we proposed a new molecular skeleton, DAB, as a fast photochromic switch based on $6 \pi$-electron photocyclization/thermal cycloreversion reaction. DAB could be easily synthesized though Suzuki-Miyaura coupling of the DAE precursor and 1,2-dibromotetrafluorobenzene. DAB underwent photochemical reaction upon irradiation with UV light and thermal cycloreversion with $t_{1 / 2}$ of $130 \mathrm{~ms}$ at room temperature. The small $E_{\mathrm{a}}$ of $66 \mathrm{~kJ} \mathrm{~mol}^{-1}$ enabled the fast thermal cycloreversion. In addition, DAB had high fatigue resistance and exhibited reactivity even in the solid state. The latter is one of the advantages of the $6 \pi$-electron photocyclization/thermal cycloreversion system because it only requires a small molecular geometry change. We believe that this work would provide a new strategy for the molecular design of fast photochromic switches and lead to the development of new functions for $6 \pi$-electron photochromic systems.

\section{Conflicts of interest}

There are no conflicts to declare.

\section{Acknowledgements}

This work was partly supported by JSPS KAKENHI Grant Numbers JP26107013 in Scientific Research on Innovative Areas "Photosynergetics" (S.K) and JSPS KAKENHI Grant Number JP16K17896 in Scientific Research for Young Scientists B (D.K.).

\section{Notes and references}

1. C. Jia, A. Migliore, N. Xin, S. Huang, J. Wang, Q. Yang, S. Wang, H. Chen, D. Wang and B. Feng, Science, 2016, 352, 1443-1445.

2. M. Irie, T. Fukaminato, T. Sasaki, N. Tamai and T. Kawai, Nature, 2002, 420, 759-760.

3. K. Matsuda and M. Irie, J. Am. Chem. Soc., 2000, 122, 71957201.

4. M. Tomasulo, S. Sortino, A. J. White and F. M. Raymo, J. Org. Chem., 2005, 70, 8180-8189.

5. M. Tomasulo, S. Sortino and F. M. Raymo, J. Org. Chem., 2008, 73, 118-126.

6. Y. Kishimoto and J. Abe, J. Am. Chem. Soc., 2009, 131, 42274229.

7. K. Fujita, S. Hatano, D. Kato and J. Abe, Org. Lett., 2008, 10, 3105-3108.

8. C. Y. Huang, A. Bonasera, L. Hristov, Y. Garmshausen, B. M. Schmidt, D. Jacquemin and S. Hecht, J. Am. Chem. Soc., 2017, 139, 15205-15211.

9. N. A. Simeth, S. Crespi, M. Fagnoni and B. Konig, J. Am. Chem. Soc., 2018, 140, 2940-2946.

10. N. Ishii, T. Kato and J. Abe, Sci. Rep., 2012, 2, 819.

11. Y. Kobayashi and J. Abe, Adv. Opt. Mater., 2016, 4, 1354-1357.

12. J. Cusido, S. Impellizzeri and F. M. Raymo, Nanoscale, 2011, 3, 59-70.

13. E. Deniz, M. Tomasulo, J. Cusido, I. Yildiz, M. Petriella, M. L. Bossi, S. Sortino and F. M. Raymo, J. Phys. Chem. C, 2012, 116, 6058-6068. 
14. F. Tong, M. P. Hanson and C. J. Bardeen, Phys. Chem. Chem. Phys., 2016, 18, 31936-31945.

15. L. Zhu, F. Tong, C. Salinas, M. K. Al-Muhanna, F. S. Tham, D. Kisailus, R. O. Al-Kaysi and C. J. Bardeen, Chem. Mater., 2014, 26, 6007-6015.

16. F. M. Raymo, Adv. Mater., 2002, 14, 401-414.

17. S. Giordani and F. M. Raymo, Org. Lett., 2003, 5, 3559-3562.

18. V. Balzani, A. Credi and M. Venturi, ChemPhysChem, 2003, 4, 49-59.

19. Y. Inagaki, Y. Kobayashi, K. Mutoh and J. Abe, J. Am. Chem. Soc., 2017, 139, 13429-13441.

20. M. Irie, T. Fukaminato, K. Matsuda and S. Kobatake, Chem. Rev., 2014, 114, 12174-12277.

21. T. Fukaminato, S. Kobatake, T. Kawai and M. Irie, Proc. Japan Acad., Ser. B, 2001, 77, 30-35.

22. C. C. Corredor, Z. L. Huang and K. D. Belfield, Adv. Mater., 2006, 18, 2910-2914.

23. C. C. Corredor, Z. L. Huang, K. D. Belfield, A. R. Morales and M. V. Bondar, Chem. Mater., 2007, 19, 5165-5173.

24. S. Kobatake, S. Takami, H. Muto, T. Ishikawa and M. Irie, Nature, 2007, 446, 778-781.

25. D. Kitagawa, H. Nishi and S. Kobatake, Angew. Chem. Int. Ed., 2013, 52, 9320-9322.

26. D. Kitagawa, H. Tsujioka, F. Tong, X. Dong, C. J. Bardeen and S. Kobatake, J. Am. Chem. Soc., 2018, 140, 4208-4212.

27. D. Kitagawa and S. Kobatake, Chem. Rec., 2016, 16, 2005-2015.

28. D. Kitagawa, K. Sasaki and S. Kobatake, Bull. Chem. Soc. Jpn., 2011, 84, 141-147.

29. S. Nakamura, S. Yokojima, K. Uchida, T. Tsujioka, A. Goldberg, A. Murakami, K. Shinoda, M. Mikami, T. Kobayashi, S. Kobatake, K. Matsuda and M. Irie, J. Photochem. Photobio. A: Chem., 2008, 200, 10-18.

30. D. Z. Chen, Z. Wang and H. H. Zhang, J. Mol. Struct. (Theochem), 2008, 859, 11-17.

31. Y. H. Yang, Y. S. Xie, Q. Zhang, K. Nakatani, H. Tian and W. H. Zhu, Chem. Eur. J., 2012, 18, 11685-11694.

32. S. Kawai, T. Nakashima, K. Atsumi, T. Sakai, M. Harigai, Y. Imamoto, H. Kamikubo, M. Kataoka and T. Kawai, Chem. Mater., 2007, 19, 3479-3483.

33. J. V. Milić, C. Schaack, N. Hellou, F. Isenrich, R. GershoniPoranne, D. Neshchadin, S. Egloff, N. Trapp, L. Ruhlmann, C. Boudon, G. Gescheidt, J. Crassous and F. Diederich, J. Phys. Chem. C, 2018, 122, 19100-19109.

34. M. Irie, T. Lifka, S. Kobatake and N. Kato, J. Am. Chem. Soc., 2000, 122, 4871-4876

35. W. J. Miao, L. H. Li, S. Lu, G. Liu and C. B. Fan, Acta Crystallogr. Sect. E: Struct. Rep. online, 2009, 65, 03003.

36. M. Milek, A. Witt, C. Streb, F. W. Heinemann and M. M. Khusniyarov, Dalton Trans., 2013, 42, 5237-5241. 